\title{
PLANT CHEMOSYSTEMATICS AND PHYLOGENY
}

\author{
B. L. TURNeR \\ The University of Texas, Austin, Texas, U.S.A.
}

\section{INTRODUCTION}

There has been a fervour of intellectual activity in botanical systematics during the past 10 years, most of this associated with new approaches to old problems. Constance ${ }^{1}$ has presented an excellent summary of this activity in his account of "Systematic Botany-An Unending Synthesis", and it need only be noted here that he recognizes three major new approaches to present-day systematics, these being (1) Chemical, (2) Numerical, and (3) Ultrastructural ("Fine Structure"). (I prefer to include ultrastructure as a subdivision of the chemical ${ }^{2}$, but at the present state of its development, and on pragmatic grounds, it would seem better to treat this approach as a subdiscipline in its own right.)

In view of the current impact of the chemosystematic approach it is perhaps appropriate to evaluate the place of this discipline amongst those of anatomy, cytogenetics, elc. Alston and Turner ${ }^{3}$ have outlincd the history of systematics by recognizing five major periods, the inception of each being characterized by the development of new concepts or approaches which have permitted the accumulation of new data and/or conceptual insights bearing on systematics generally. Briefly these are: (1) the Megamorphic (400 B.C.1700 A.D.), (2) the Micromorphic (1700-1860), (3) the Evolutionary (1860-1900), (4) the Cytogenetical (1900-1960), and (5) the Biochemical $(1960-?) \dagger$. It should be obvious that each of these periods has made, and continues to make, important contributions to systematics; in fact it might be said that each has contributed in proportion to its time-span since ushered in (Figure 1). Certainly the development of succeeding periods has depended upon those preceding, and it is highly likely that any successful evaluation of the biochemical must depend upon the mega- and micro-morphical data at all taxonomic levels.

That the early 1960s has truly ushered in the Biochemical Era can be ascertained from the fact that four major chemosystematic texts appeared during this period ${ }^{3-6}$ as well as several major review articles ${ }^{7-14}$. An additional catalytic factor in plant systematics has been the establishment of the periodical Phytochemistry (commenced, 1961). Most of the articles published in this journal have considerable bearing on the field of plant chemosystematics. Finally, it should be noted that an International Committee on Chemotaxonomy was formed during this period-a joint association of the formal Committees of Chemotaxonomy of the Organic Chemistry Division of

$\dagger$ Numerical taxonomy ${ }^{15}$ does not rate a position in the hierarchy since, as indicated by Constance ${ }^{1}$, it furnishes no new data, and in concept it is pre-Darwinian. 


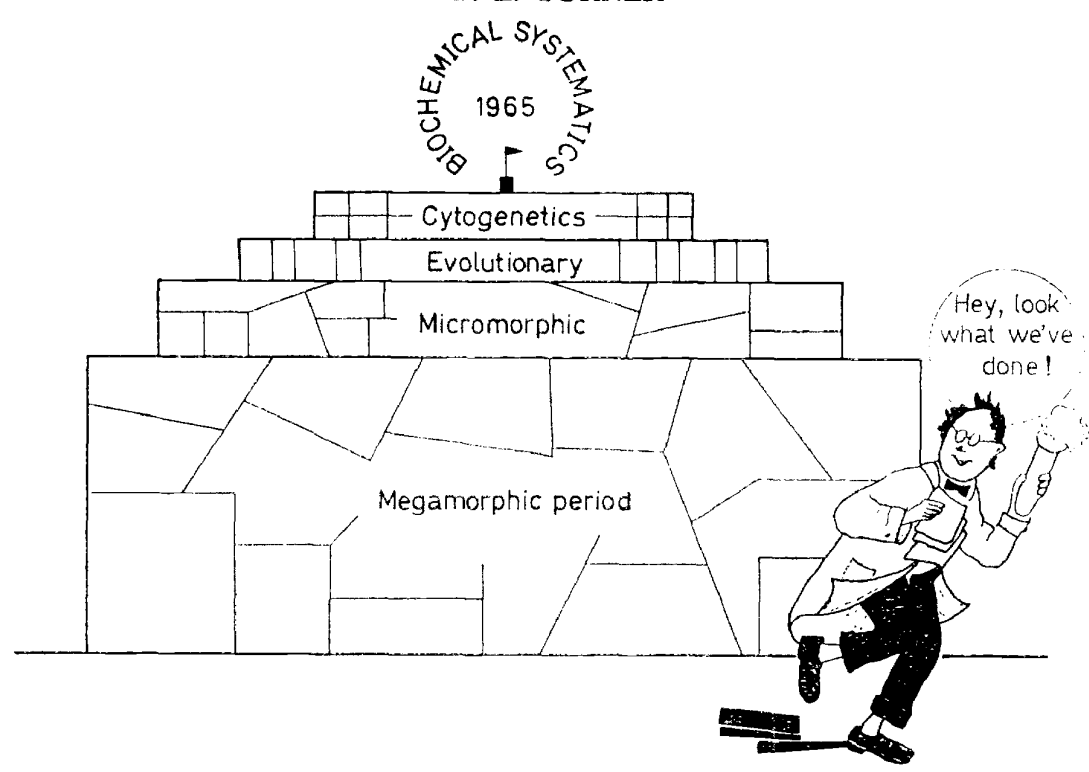

Figure 1. A chemosystematic perspective-the actual contribution of chemical data to the "taxonomic pyramid" in the year A.D. 1965. Compared to the megamorphic base, the chemical block at the apex has been exaggerated; additional explanation in text

the International Union of Pure and Applied Chemistry and that of the International Association of Plant Taxonomists ${ }^{16}$.

Botanical chemosystematics did not develop full blown, for many early workers attempted to use the meagre data then available for taxonomic purposes $^{17}$. Rather its emergence has coincided with the development of both rapid and relatively simple techniques for chemical isolations such as paper and gas-liquid chromatography. The chemosystematist for the first time could afford to undertake the broad samplings that are so necessary before meaningful generalizations can be made. As indicated by Erdtman ${ }^{18}$, most organic chemists are interested in nut cracking, not nut gathering. The chemosystematist surely must be interested in both aspects, hence the need for close collaboration between workers in these fields.

Such developments are not solely responsible for the surge of recent activity in chemosystematics, rather it is likely that enthusiastic acceptance, at least by taxonomists, has depended as much on its demonstrated contribution to the solution of specific systematic problems. Unfortunately, publications in which chemosystematics have helped solve taxonomic problems are relatively few, but their numbers are increasing rapidly and it seems likely that, as familiarity with the relatively simple chromatographic techniques increases, there will be a deluge of chemosystematically oriented articles, comparable to those ushered in by the Cytogenetical Period.

This accumulation of chemical data cannot be ignored by the plant taxonomist. The latter must become familiar with not only the molecular structure of compounds, but he should also possess some familiarity with biosynthetic pathways leading to their origin and, in general, appreciate the 


\section{PLANT CHEMOSYSTEMATIGS AND PHYLOGENY}

kind of conceptual thinking that leads from triplicate sequences in the DNA molecules to amino acid sequences in proteins to the catalytic activity of the enzymes themselves. Yet it is true that the present day taxonomists are largely ignorant of these kinds of data. Their training has not emphasized a molecular approach to systematics and for the most part they have chosen to ignore the data already assembled, much less embark on selected studies of their own. Likewise, organic chemists who attempt to apply their data to systematic problems can gain better perspective if they become familiar with the conceptual basis of modern biological and systematic thinking, especially at the populational or evolutionary level. Other areas in which the chemist needs enlightenment have been covered by Professor Hegnauer in the present symposium. In fact, the negative attitude towards chemical data expressed by some plant taxonomists can be traced to the naîve taxonomic conclusions of chemists of an earlier period and persisting even today ${ }^{19}$, in spite of adequate admonitions ${ }^{8}$ from chemists themselves. Hopefully this situation will change with the next generation thus permitting maximum interplay between systematics and organic chemistry. Indeed, it is already clear that natural plant product chemistry is being welcomed into biology departments, to the profit of both disciplines.

If chemistry assumes an increasing role in taxonomic thought and practice, one might well ask how molecular data can contribute most to systematic problems. Should these be applied towards the elucidation of evolutionary or phyletic problems or treated as unit data in a purely phenetic or numerical approach to classification? Chemical data possess a statistical objectivity ${ }^{20}$ applicable to phyletic problems unobtainable from purely morphological studies (e.g., the amino acid sequence studies of cytochrome $c$, haemoglobin, myoglobin, etc. $\left.{ }^{13}\right)$. In fact, the unique contribution that chemistry can make to systematics is that of providing a less than intuitive approach to the phyletic relationships of the higher categories generally. To reduce chemical data to mere listings in a purely numerical system would be getting the least out of the most. In order to appreciate this statement I would like to discuss, briefly, the two schools of thought, numerical taxonomy versus phylogeny, that currently hold forth among taxonomic circles.

\section{NUMERIGAL vs. PHYLETIC GLASSIFIGATION}

It is a curious fact that, in spite of the almost universal acceptance of the evolutionary theory by biologists, there exists today a number of taxonomists who are opposed to ${ }^{15}$ (or at least despair at the prospects of attempting ${ }^{21}$ ) classifying systems based on phyletic considerations. This school of workers would prefer to erect a so-called "natural" system in which essentially morphological data are quantified and computerized such that supposedly highly objective groupings might be made. The results may or may not reflect phyletic groupings and as a consequence this general approach to classification has been referred to as numerical taxonomy ${ }^{15}$. The pros and cons of the purely numerical versus phyletic approach to systematics has been amply expounded by experts in the area ${ }^{22-24}$ and it need only be noted here that the phyleticists seem to have carried the day. At least Sokal, the principal spokesman for the phenetic (or numerical) approach, has recently 


\section{B. L. TURNER}

turned his attention to numerical methods for the detection of "branching sequences in phylogeny" and only admits tacitly that a "phenetic basis is preferable for classification in this narrow sense [an arrangement of organized nature into categories for the convenience of biologists] until an operational system, combining cladistics [i.e., phylogeny as used here] and phenetics can be established (italics mine) ${ }^{25}$. A view that most plant taxonomists would ascribe to, since this is exactly what they have been about for years; phenetic systems must necessarily serve as the initial model; the latter is translated into a hypothetical phyletic Model as new insights are gained, especially by the kind of a posteriori judgements referred to by Mayr ${ }^{26}$ and through data which are difficult if not impossible to quantify such as that obtained from phytogeographical and cytogenetical considerations. Nevertheless, for the taxonomy of the plant kingdom, and in particular for that of the flowering plants, the numerical approach has held a certain attraction, mainly because fossil sequences are difficult to come by (the ultimate proof of phylogeny according to many workers) and the arrangement of the higher categories (i.e., families and orders) has received a variety of differing treatments, in spite of the fact that each is purportedly phyletic in nature. Yet it is not the phyletic evidence that is the cause of the problem, rather it is the morphological complexity itself that has lead to such differing interpretations. It is unlikely then that purely numerical treatments, using morphological data, will resolve to any great extent the more vexing positional problems.

But, after all, is the chemist really interested in evaluating his data against hypothetical phyletic models? Perhaps he would be just as content to contribute these as unit data in a computerized numerical model ${ }^{26}$. To me the answer is clear enough, for it seems that most chemists are interested not only in the distribution of compounds, but also in their biosynthetic pathways, whether these pathways are advanced or primitive and where, in fact, existing pathways might have branched out of those pre-existing, etc. Indeed, on a character basis they are as phyletically minded as most evolutionary taxonomists ${ }^{27}$. Besides, these are intellectual matters. If evolution has been a fact and if the positional relationships of present day taxa reflect that process, then as scientists it is our responsibility to at least attempt to detect those arrangements.

In the discussion that follows then, the contributions of chemosystematics to plant taxonomy, both present and future, are taken to be primarily phyletic. These will be discussed under two general headings, Micromolecular and Macromolecular, depending on the relative molecular weight of the compounds under consideration. This seems a convenient way to organize current data since these two groups of compounds demand quite different techniques and often call for differing interpretations of otherwise comparable information $\dagger$.

† Lanni ${ }^{11}$ distinguishes only two kinds of taxonomy, molecular and classical: the former uses macromolecular data, either directly or by implication, to determine the base sequences of genetic material for comparative purposes; classical taxonomy using the remaining properties. Of course, such a rigid distinction would exclude micromolecular compounds. But molecules are molecules and perhaps Lanni would admit to the breakdown of molecular taxonomy into the two headings suggested here. Even so, there would be all shades of macromolecularism, grading from the smallest peptide through the aggregational macromolecules which make up the cellular organelles themselves. 


\section{PLANT CHEMOSYSTEMATICS AND PHYLOGENY}

\section{MIGROMOLECULAR SYSTEMATICS}

Most of the early chemosystematic literature, and much of the present, has concerned itself with the mere notation of the distribution of relatively simple compounds from only one or, less often, several collections of a given taxon. Among the more popular small molecular weight compounds investigated in this fashion have been those of amino acids, alkaloids, terpenoids, and flavonoids. These four chemical classes are widespread among plant groups but in each may be found certain subclasses which are restricted to closely related taxa. On the other hand, certain compounds in these groups occur in taxa which are clearly unrelated and it can only be assumed that their appearance in the organisms concerned reflect more the vagaries of the metabolic systems that produce them rather than they do phylogeny or gene homology. Some of these compounds, such as the 20 protein amino acids, are ubiquitous and hence of little or no value for taxonomic purposes. At the other extreme, one may point to the free amino acid lathyrine, which has been found in only 11 species of the genus Lathyrus, in spite of extensive surveys for this compound among plant groups generally ${ }^{28}$.

Like morphological characters, chemical characters are cften variable, hence one of the first objectives in a chemosystematic survey is to establish the reliability of the data, both within and between populations. Too few of the early workers took such pains, and as a consequence, many premature systematic conclusions were drawn from incomplete data. As much care should be taken in acquiring chemical data as is taken for morphological measurements. Thus, for chromatographic surveys extracts for analyses should be made from comparable organs in comparable stages of development, preferably under comparable environmental conditions. This has been amply emphasized by Erdtman ${ }^{8}$ and others.

Nevertheless the question which has been most often raised by workers in chemosystematics has been that of the effect of environmental variables on chromatographic patterns ${ }^{29}$. This question has been effectively answered for flavonoids by growing asceptically cultured, uniclonal-derived populations of Spirodela oligorhiza and other aquatic species under a wide range of controlled environmental conditions ${ }^{30}$. In nearly all instances the flavonoid patterns of the taxa were unaffected by these variables; indeed the frond morphology was more often modified than were the chromatographic patterns, and identification in such instances could be more surely made by chromatography than by visual inspection of the fronds themselves. This is not to say that these compounds are never affected by such variables; as in morphology, the phenetypic expression of a given character should be reassessed as one undertakes the study of yet other taxa.

\section{Hybridization}

Most chemists, in that they are not generally involved with purely systematic problems, are probably unaware of the widespread occurrence of natural hybridization among plant species generally, consequently they have perhaps not appreciated the significance of chemical data for resolving problems of natural hybridization. Morphological and cytogenetical 


\section{B. L. TURNER}

techniques can be used to detect hybridization in most instances ${ }^{31}$ but there are situations where chemical data can be decisive in dealing with such problems, particularly where complex hybridization is encountered. Thus, Alston and Turner ${ }^{32}$, when confronted with a natural hybrid swarm involving three species of the genus Baptisia, were able to show by twodimensional paper chromatography that what appeared to be on morphological grounds, complex three-way hybridization and backcrossing was in

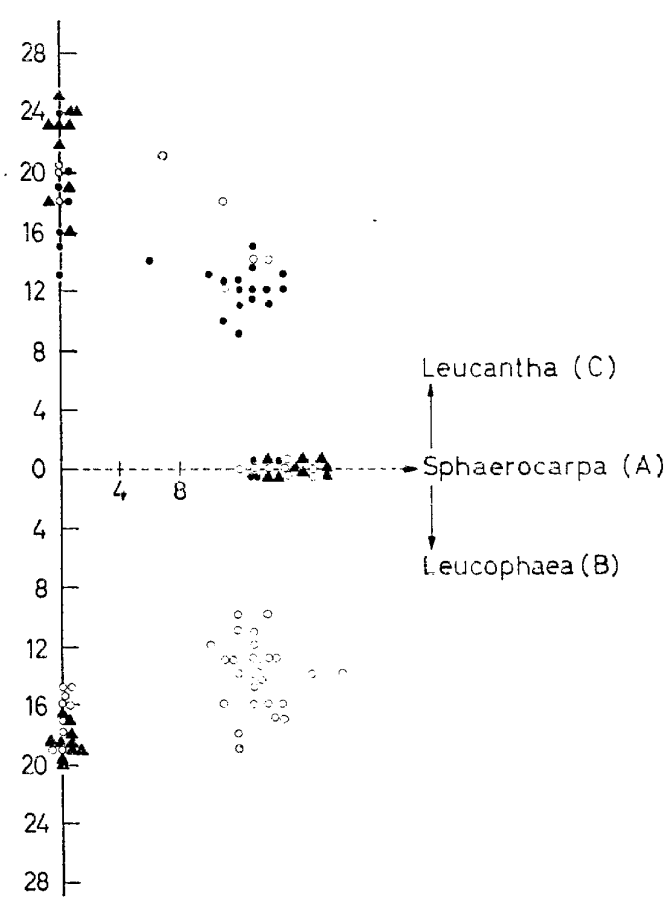

Figure 2. A three-way plot of individual hybrid types and pure species of Baptisia. Open circles indicate plants from a tri-hybrid population, closed triangles indicate miscellaneous supplementary plants from pure populations and closed circles indicate the additional (supplementary) B. leucantha $\times B$. sphaerocarpa hybrids from other populations. Points along the horizontal $(\mathrm{X})$ axis represent the number of compounds recognized of $B$. sphaerocarpa; points along the vertical $(\mathrm{Y})$ axis represent (above) the number of compounds recognized of $B$. leucantha and (below) the number of compounds recognized of $B$. leucophaea. Hybrids fall at some angle between the $\mathrm{X}$ and $\mathrm{Y}$ axes (from Alston and Turner ${ }^{32}$ )

reality a less complex situation in which crossing was mostly two-way: for example, the sympatric species A, B, and $C$ were found in the following hybrid combinations, $\mathrm{A} \times \mathrm{B}$ (and backcrosses), $\mathrm{A} \times \mathrm{G}$ (and backcrosses) but the combination $B \times C$ (or backcrosses of the $B$ genome into that of the $\mathrm{C}$ or vice versa), which was predicted on morphological grounds, could not be detected (Figure 2). An even more complex natural situation was reported $^{\mathbf{3}}$ in which four species of Baptisia occurred together and, within a several acre field, all six of the possible two-way $F_{1}$ combinations were detected, along with several backcrosses. It is doubtful that these hybrid 


\section{PLANT CHEMOSYSTEMATICS AND PHYLOGENY}

populations could have been so successfully analysed without the aid of paper chromatography. One reason that the chemosystematic approach, using flavonoids in this instance, has been so successful in Baptisia is that, unlike morphological variables which are usually expressed through multiple gene systems ${ }^{34}$, the presence or absence of flavonoid components are usually governed by genes expressing dominance or recessiveness, the appearance of a compound generally reflecting dominance. Thus, the chromatographic pattern of an $\mathrm{F}_{1}$ between two species of Baptisia with differing flavonoid patterns is expressed additively (Figure 3), i.e., the flavonoids found in the hybrid are the same as those found in both the parental types (analogous to chromosomes in amphiploids). Smith and Abashian ${ }^{35}$ have reported the same phenomenon for alkaloids in Nicotiana hybrids, although several workers ${ }^{36,37}$ have reported occasional synthetic hybrids where complementations of alkaloids were not found. However, when a large number of secondary substances are involved, it is unlikely that occasional variation in the anticipated patterns will prove grossly misleading. Thus, Parks ${ }^{38}$ attempting to find whether striking differences in visual petal pigmentation in Gossypium might be due to relatively simple mutations which affect the entire spectrum of flavonoids, concluded "that flower-colour mutans which grossly affect visual colour of the flower do not obscure the basic array of flavonoids of the species studied, and that the species may be positively identified by the residual array of pigments not affected by particular alleles." In fact, McHale and Alston ${ }^{39}$ working with selected species of Baptisia have suggested that for the detection of $F_{1} s$, the chemical data may be more instructive than morphological data, for what they took to be unequivocal $F_{1} s$ on chromatographic grounds, appeared to be collections which morphologically strongly approached one or the other parental types.

One of the more spectacular studies of hybrids using chromatographic techniques has been that of Smith and Levin ${ }^{40}$ for the genus Asplenium. These authors showed that the allopolyploid hybrid, A. $\times$ kentuckiense, which is believed to combine the genomes of three diploid species, has a chromatographic profile which is the additive combination of the distinctive profiles of each of the Asplenium species which contributed to the three-way hybrid. Their results agreed in all respects with the concept of reticulate evolution as proposed for this taxon by other workers, who used primarily morphology and cytology in their studies.

Hybrid studies of a similar nature, but with less striking documentation, have been made for species of Viola ${ }^{41}$; Coprosma ${ }^{42}$; Zinnia ${ }^{43}$; Lotus ${ }^{44}$; Tragopogon ${ }^{45} ;$ Phlox $^{46}$; and Vernonia ${ }^{47}$. But at least a few workers have not found flavonoids particularly useful in the documentation of hybrids, thus Stromnaes and Garber ${ }^{48}$, working with Collinsia, could not detect $F_{1}$ s by this method even when the parental types possessed different chromatographic profiles.

Quantitative variation in chemical components, as opposed to qualitative, may also be used for the detection of hybridity as indicated by the excellent populational studies of $\mathrm{Mirov}^{49,50}$, Bannister et al. ${ }^{51}$, and Forde ${ }^{52}$. These workers have shown that $\mathrm{F}_{1}$ hybrids between different species of Pinus possessed quantities of terpenes more or less intermediate to those possessed 


\section{B. L. TURNER}

by the parental types, but they cautioned against the utilization of such data for the detection of $F_{2}$ hybrids and backcross types since the quantitative variations, at least in part, seemed to be under complex genetic control. A similar study of a more restricted nature is that of Stone et al. ${ }^{53}$ who used the quantitative variations of five fatty acids to help establish the hybrid nature of Carya $\times$ lecontei.

Aside from the documentation of hybrids per se, chromatographic data have provided a convenient means for the detection of introgression. As indicated by Anderson ${ }^{31}$ the detection, by morphological criteria, of the influx of genes from one taxon into another by hybridization and backcrossing is most difficult, mainly because the inheritance of such characters is multifactorial and one or a few such genes, when incorporated into the variable gene-plasm of an adjacent organism, are difficult to pick up, for the environmental variables and the phenotypic plasticity of most plant populations are such as to preclude their discovery even by rather sophisticated statistical means.

When the species investigated possess quite different flavonoids, the relatively simple genetic control of such compounds ${ }^{54}$ ought to make possible the detection of both allopatric and sympatric introgression. Horne ${ }^{55}$ has suggested that certain regional variations in the flavonoids of Baptisia nuttalliana might be due to introgression; and Baetcke ${ }^{56}$, through his chromatography study of over 1400 plants of a hybrid swarm involving Baptisia leucophaea and $B$. sphaerocarpa, in my opinion, has demonstrated sympatric introgression between these species.

Gas chromatographic studies promise to be an important approach for the analysis of allopatric introgression (where two essentially geographically contiguous species exchange genes regionally as a result of usually long-time hybridization and backcrosses). The latter is difficult to detect by purely morphological studies, but the sensitivity of the gas chromatographic apparatus should make populational samples easy to quantify, especially where terpenoid compounds have been selected for examination. Von Rudloff ${ }^{57}$ has been able to get reliable terpenoid data from a single conifer leaf and it should prove feasible to re-examine with chemical data ${ }^{58}$ the now classical example of allopatric introgression in Juniperus.

The chromatographic method, at least for the detection of flavonoids, alkaloids, and most terpenoids, need not be limited to fresh material. Dried specimens as obtained by the usual herbarium procedures are often sufficient; in fact, using flavonoids, the hybrid nature of herbarium specimens over 85 years old or more may be established ${ }^{59}$. Finally, it should be noted that macromolecular data have also been used to document hybridization and several cases are noted in the section on Macromolecular Systematics (below).

\section{Phyletic groupings}

In the discussion above, emphasis has been placed on the utility of chromatographic data for the detection of hybridization. This is one area of systematics where the chromatography of secondary compounds has made significant contributions to the phyletic process. Such an approach does not 

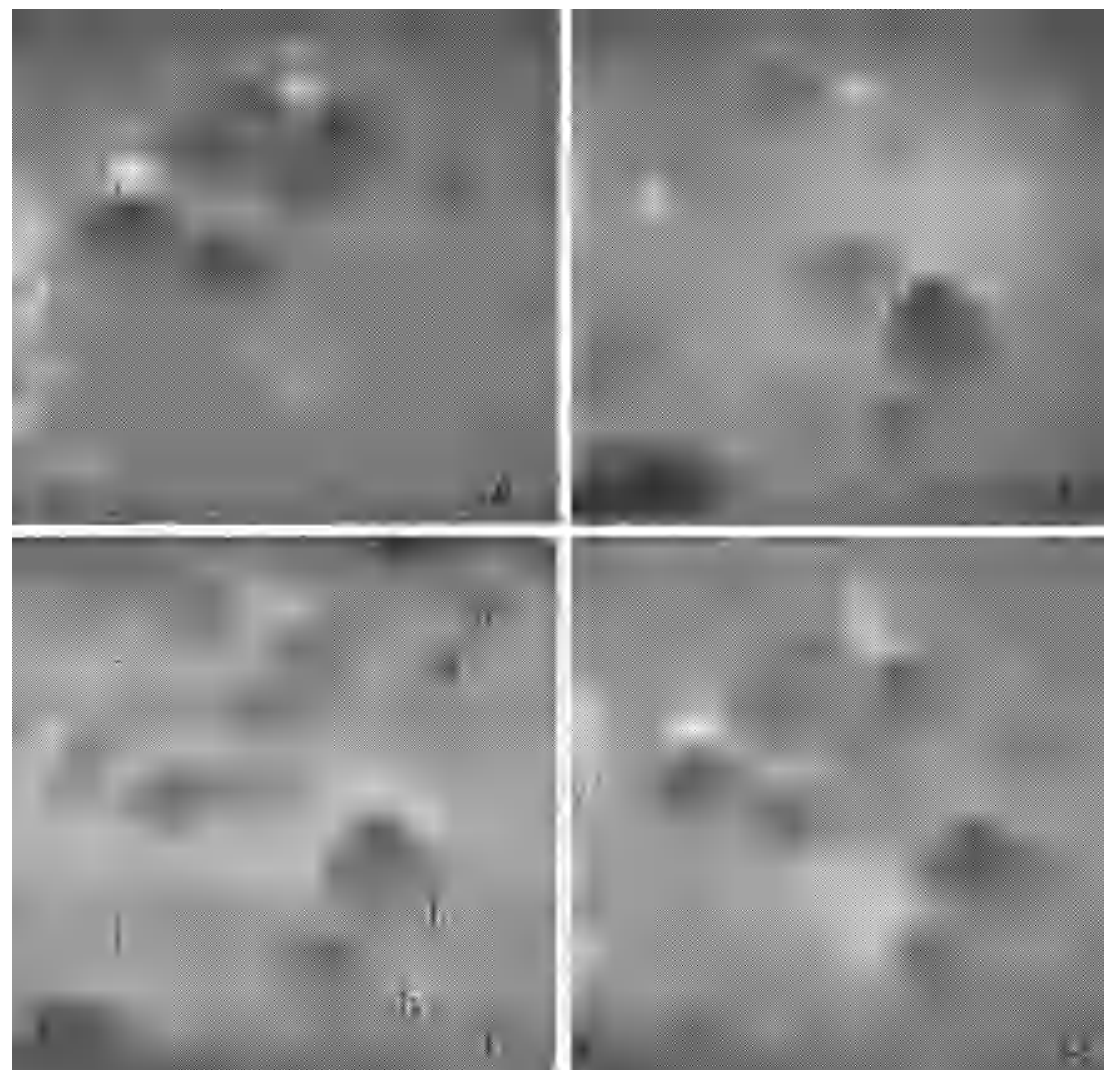

Figure 3. Chromatographic patterns of leaf extracts from Baptisia leucantha and B. sphaerocarpa and their $\mathrm{F}_{1}$ hybrid. $\Lambda$, leucantha; $\mathrm{B}, B$. sphaerocarpa; $\mathrm{C}$, natural hybrid; $\mathrm{D}$, in vitro "hybrid" (obtained by mixing leaf extracts of the two species prior to chromatography). The letters $\mathrm{L}$ and $\mathrm{S}$ refer to the origin of the spot from either B. leucantha (L) or B. sphaerocarpa (S); the letter h refers to "hybrid spots" which appear in the natural hybrid (for biological reasons ${ }^{60}$ ) but do not occur in the in vitro "hybrid". Adopted from Alston and Hempel, J. Hered. 55, 267 (1964) 


\section{PLANT CHEMOSYSTEMATICS AND PHYLOGENY}

require that the compounds be identified chemically, although such information might be desirable in attempting to evaluate the significance of any new compounds which might be detected in hybrids ${ }^{60}$ (Figure 3).

While the relative differences of chromatographic profiles (e.g., general comparative studies of restricted groups of compounds such as flavonoids which are widely distributed among plants) might be of some utility in distinguishing between taxa ${ }^{61-63}$, the spot data, taken alone and without chemical determinations, are unlikely to contribute any real phyletic insights.

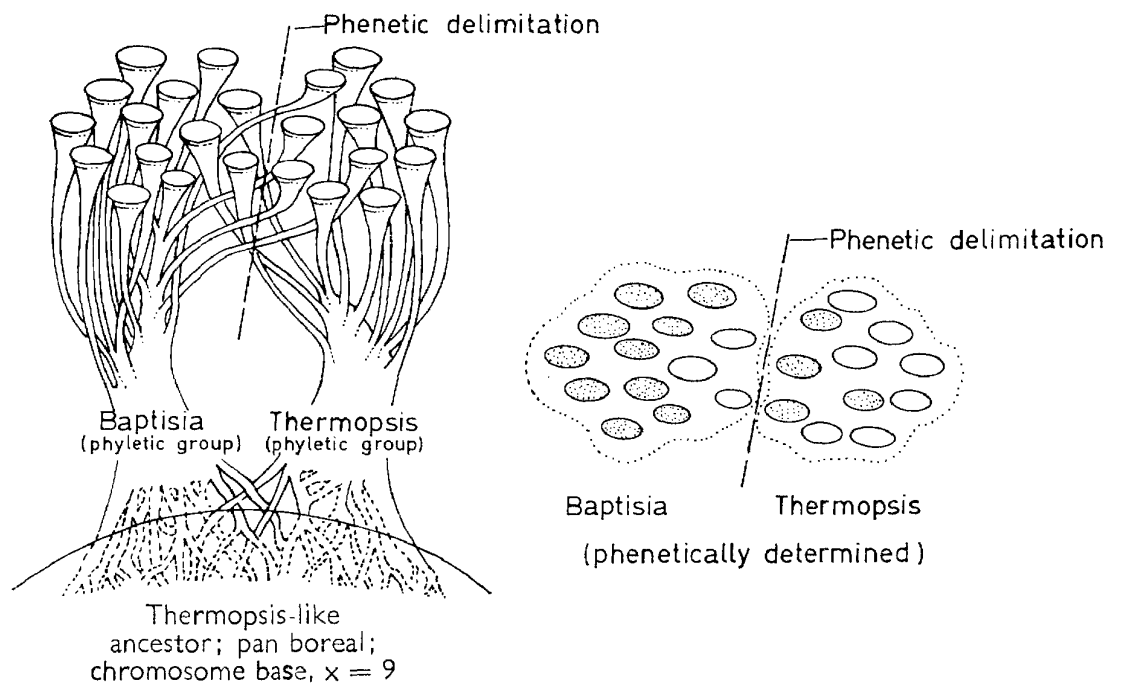

Figure 4. Hypothetical relationship of present day Baptisia and Thermopsis species. An evolutionary treatment would attempt to group the species into two monophyletic taxa (indicated by stippling and non-stippling). A purely numerical or phenetic treatment (i.e.,

without phyletic considerations) might group the species into two polyphyletic genera

Thus one must distinguish between recognition, circumscription and arrangement. The former are only rarely affected by phyletic thinking; the latter often so. Phylogeny then, to most plant systematists, is the business of arranging taxa or groups of taxa such that their taxonomic position one to the other reflects best the genetic ancestry of those taxa. As indicated by Henning ${ }^{24}$, fossil records are not prerequisite for evolutionary groupings of extant taxa. To make this point, I would like to discuss briefly two possible approaches, phenetic vs. phyletic, to the arrangement of the species which comprise the genus Baptisia.

Baptisia, as currently treated, is composed of 16 easily recognized species, the members of which are more closely related one to the other than any is to yet another taxon. The taxonomic cliché indicated by italics serves as the conceptual "philosophy" of both phenetic and phyletic workers, with one important difference: the phyleticists would urge that the arrangement of relationships arrived at be made on evolutionary grounds; the pheneticists presumably would not bother to ask the question. Figure 4 illustrates, albeit crudely, the problem for Baptisia and the closely related genus Thermopsis. On purely phenetic grounds, say by numerical means where all characters are given 


\section{B. L. TURNER}

equal weight without priori considerations of any sort, the species which comprise these genera might well be grouped differently than they are at present. Indeed, when I first came across a rare species of Thermopsis in the south-eastern United States I thought I had discovered an undescribed species of Baptisia, so alike are these genera in vegetative and floral characters. I drew up a description of the supposed new species, but since the material lacked pods I returned to the population the following season and discovered that its fruit character was diagnostic of Thermopsis. This occasioned a re-examination of all my evidence, including the characters of Thermopsis, and I concluded that the population concerned was not a species of Baptisia with flat pods (a key character used to distinguish the genera; Baptisia possesses inflated, globose to cylindrical pods); rather it was a bona fide Thermopsis. Indeed, the species had already been described as belonging to that genus by an earlier worker. (I cannot help but add that on phenetic grounds I might have at least got a name change for my efforts; fortunately for nomenclature stability, my phyletic views prevailed.)

Quite apart from the morphological characters, there are other compelling reasons for treating Thermopsis and Baptisia as distinct phyletic groupings. For example, Thermopsis is a widespread boreal group occurring at high elevation (mostly in tiaga or timberline plant associations) from India across China into Russia, Alaska, western North America with an isolated series of species in the Appalachian Mountains of the eastern United States. Many of its species are isolated clonal relics, possessing little variability and only rarely showing evidence of evolutionary vigour. Baptisia, on the other hand, is restricted to the eastern United States and adjacent Canada, occurring at low elevations mostly in relatively warm moist regions, occupying floristic provinces which are believed to be younger than those occupied by Thermopsis. Its species are highly variable, exchange genes readily with other populational aggregates, reproduces readily from seed, increases rapidly in disturbed areas and, in general, acts as an evolutionarily aggressive taxon.

Phyletically speaking one might go further and suggest that a Thermopsislike ancestor gave rise to Baptisia, perhaps from species of Thermopsis not too unlike those which persist today as relics in the Appalachian mountains. To obtain Baptisia one need only imagine an ancestral gene pool which, through successive changes, gave rise to populations with inflated pods, physiological adaptions to warm, moist habitats and whatever else it took to become successful in the new habitats which appeared following the post early Tertiary appearance of the coastal land masses of the southeastern United States. The evolution of Baptisia, as it is known today, was seemingly accompanied by an accelerated change in its vegetative features, the species possessing trifoliolate (presumably primitive) bifoliolate, unifoliolate and even perfoliate leaves. In addition, its pods have progressed from an erect, inflated, linear pod (presumably primitive) to a pendulous, globose, papery to woody pod. None the less, this remarkable proliferation in leaf and fruit types has not diminished the ability of these species to exchange genes through hybridization, for whenever two or more of the species grow together or near each other, hybrids can usually be found. (At those few sites in the Appalachian region where Thermopsis and Baptisia grow together, hybrids have not been detected.) In short, one simply cannot equate vegetative 


\section{PLANT GHEMOSYSTEMATICS AND PHYLOGENY}

characters in the two genera, for their evolutionary patterns, as described above, seem to have been different. Taking all the evidence, it is apparent that there are two distinct phyletic series, Baptisia and Thermopsis; some species of Baptisia may look like Thermopsis and vice versa, but in my opinion, such resemblances are due either to parallelism from ancestral prototypes or to convergence.

It should prove instructive to evaluate the chemical data against the phyletic views expressed above. Unfortunately, Thermopsis has not been sufficiently investigated to permit meaningful evaluations. Thermopsis does possess a rich pool of flavonoids ${ }^{64}$, however, and a comparison of specific molecular types with those of Baptisia may permit some insight into the origin of the latter genus (i.e., whether Baptisia is a monophyletic group arising out of a Thermopsis-like ancestral stock, relics of which still persist in the Appalachian Mountains; or whether Baptisia is polyphyletic, the extant species having arisen out of a number of Thermopsis-like ancestral lines, relics of which persist in the timberlines of Nepal, tiaga of Siberia and the mixed evergreen deciduous forest of the eastern United States).

The infrageneric distribution of flavonoids in Baptisia (Table I) does suggest, however, that certain specific groupings are more likely than others. Interestingly enough, the chemical data support an alignment based on characters of the pod-an alignment which would have been difficult to detect using vegetative features as important criteria in the morphological evaluations. A possible exception is that of $B$. megacarpa. This species is a rarely encountered species of the Appalachicola River area of western Florida, a region renowned for its relic floristic elements. $B$. megacarpa is included with the white flowered species ( $B$. alba and $B$. leucantha) on both its fruit and vegetative features (vegetatively like both $B$. leucantha and $B$. alba; fruit similar to $B$. leucantha) but floral characters suggest a relationship to the B. leucophaea series (Table I), as do the flavonoids. In fact, it is likely that in placing the species with $B$. alba and $B$. leucantha we have been unduly impressed with the vegetative characters and perhaps superficial appearance of the fruit characters. In hindsight, we seem to have ignored the floral characters; but the recently assembled flavonoid data have forced us to take a second look and it might be that the phyletic position of $B$. megacarpa is, after all, with the $B$. leucophaea alliance. At the least the chemical data do suggest that it is an exceptional species, perhaps a relic from some ancestral complex which gave rise to both the $B$. leucantha and $B$. leucophaea groups; certainly it is not a recent populational derivative of the former species.

In addition to the flavonoids, at least 15 lupine alkaloids have been reported for Baptisia and Thermopsis ${ }^{65,66}$. Both genera possess the tricyclic compounds cytisine, methylcytisine and anagyrine as their major alkaloids and consequently these data have proven to have little systematic valuc at the generic level or lower. The alkaloids do however indicate that the two genera (and their northern hemisphere relatives Piptanthus and Anagyris) are perhaps rather distantly related to the tribe Podalyrieae (where they are usually placed), standing instead somewhere between the southern hemisphere elements of that tribe and the tribe Genisteae (Figure 5). In this connection it should be noted that Thermopsis possesses a larger pool of alkaloids than does Baptisia, many of these of the tetracyclic type 


\section{B. L. TURNER}

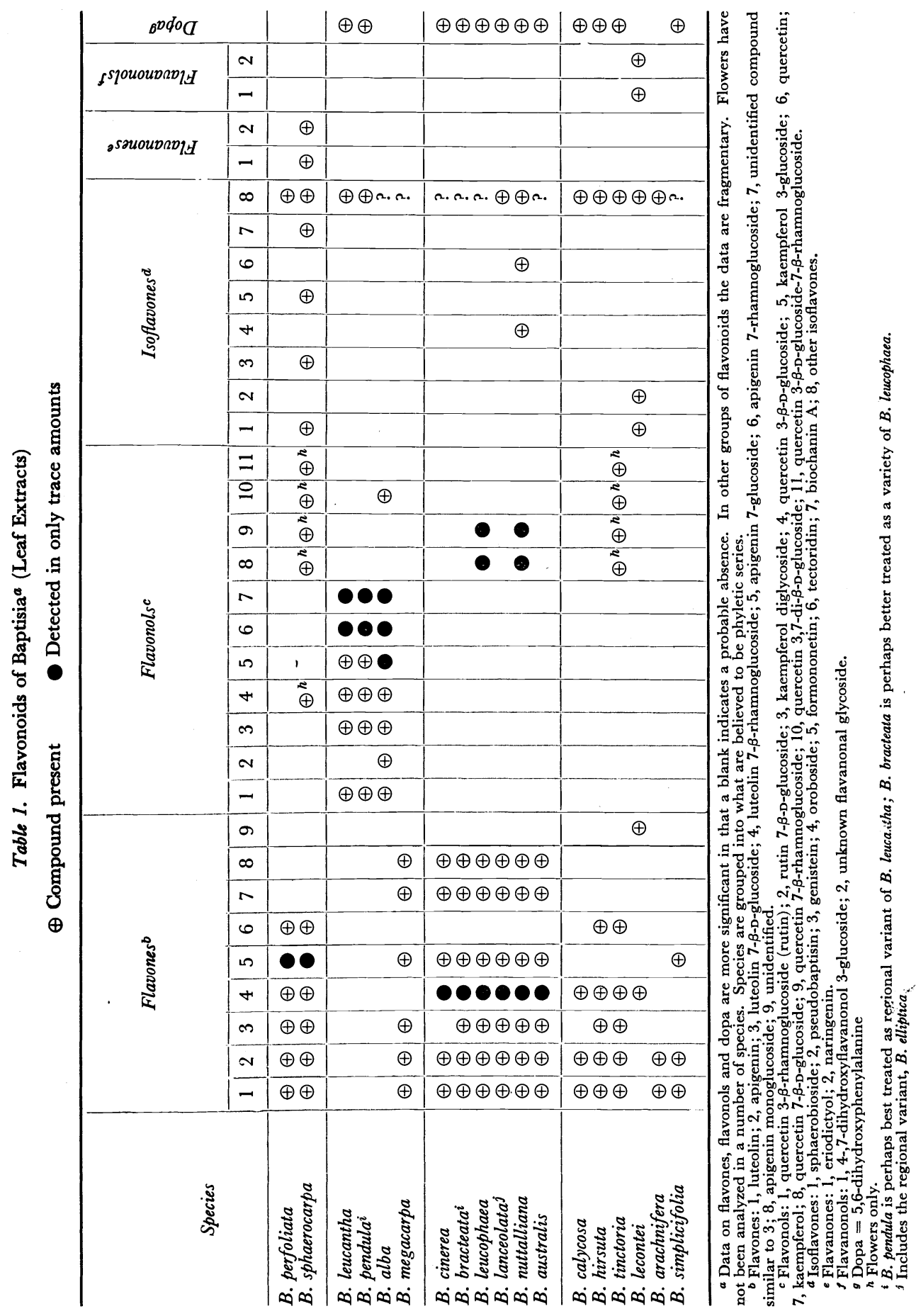




\section{PLANT CHEMOSYSTEMATICS AND PHYLOGENY}

(e.g. sparteine). Tetracyclic lupine alkaloids are believed to be biosynthetic precursers to the tricyclic type and this information, along with the morphological and ecogeographical data discussed above, again speaks for a Thermoksis-like element as the older phyletic stock. That both genera are in turn related to the tribe Sophoreae may be ascertained from the fact that Sophora possesses, as minor alkaloids, at least five of the approximately eight alkaloids common to Baptisia and Thermopsis (Table 2). Lupine alkaloids are notably absent in the southern hemisphere Podalyrieae, only a single compound (lupanine) reported to date.

\section{Papilionoideae}

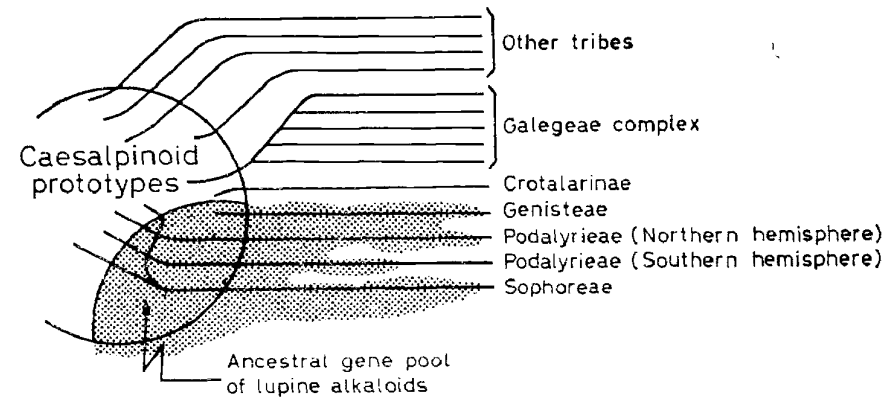

Figure 5. Tribes of the Leguminosae which contain lupine alkaloids, arranged according to hypothetical phyletic affinities ${ }^{66}$

I have chosen Baptisia and Thermopsis to discuss the bearing of microchemical data on systematic problems because of my familiarity with the morphology of the groups. However, the kind of phyletic problems raised by these two genera can be found again and again in vascular plants. For example, Vicia and Lathyrus are distinguished primarily by characters of the ovary. If it were not for an intuitive weighting of these two characters, certain elements of Vicia might easily go into Lathyrus and vice versa. That is, a purely phenetic treatment would tend to obscure the phyletic relationships. Bell's work ${ }^{67}$ on the distribution of free amino acids in these two genera is particularly instructive; indeed, his data clearly reinforce the treatment of these taxa as distinct phyletic lines, implicit in the a posteriori judgements, from morphological data, which treat the taxa as distinct genera.

One of the more intriguing studies in which micromolecular data have provided phyletic insights, perhaps unobtainable by purely exomorphic means, is that of McClure ${ }^{68}$ on the Lemnaceae (Duckweed family). A number of flavonoids occur in the four genera, Spirodela, Lemna, Wolffia, and Wolffiella, which comprise the family, and the distribution of these compounds among the genera is particularly interesting.

To appreciate the data, however, a brief taxonomic account of the family must be given. It is a wholly aquatic family belonging to the monocotyledonous groups. The included species are highly reduced, both in size and outward complexity. Some of the species (e.g., Wolffi spp.) measure less than $2 \mathrm{~mm}$ across, being devoid of roots, apparent stems or leaves; indeed, they might be described as minute, green vegetative balls (the species flower but rarely). Most workers agree that the Lemnaceae has been derived from 
B. L. TURNER

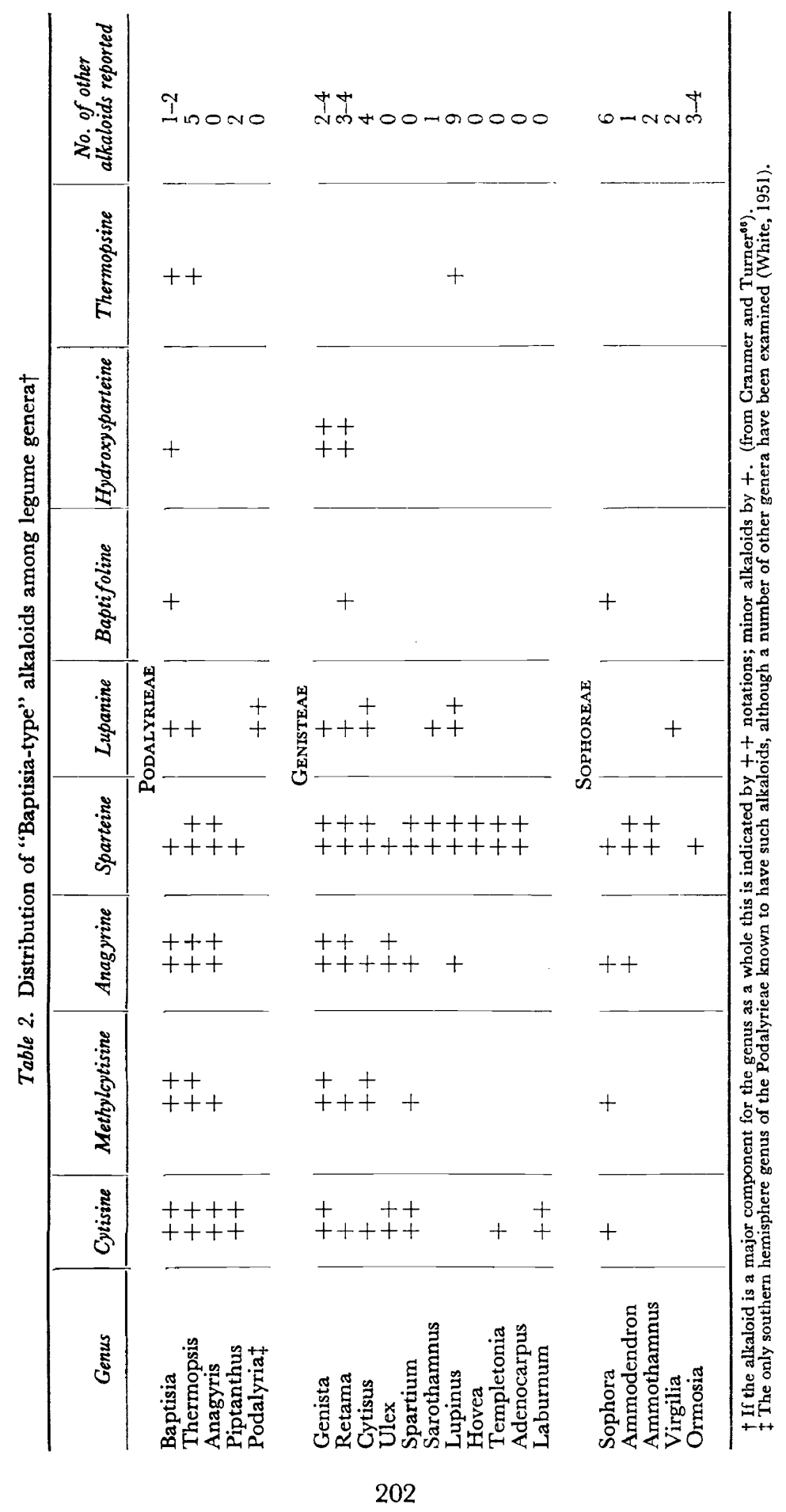




\section{PLANT GHEMOSYSTEMATICS AND PHYLOGENY}

terrestrial ancestors and that within the family there has been a phyletic trend toward increasing simplicity through reduction ${ }^{69-71}$. Thus Spirodelalike species are believed to have given rise to Lemna-like species and the latter to the most highly reduced, Wolfia and Wolffiella (Figure 6).

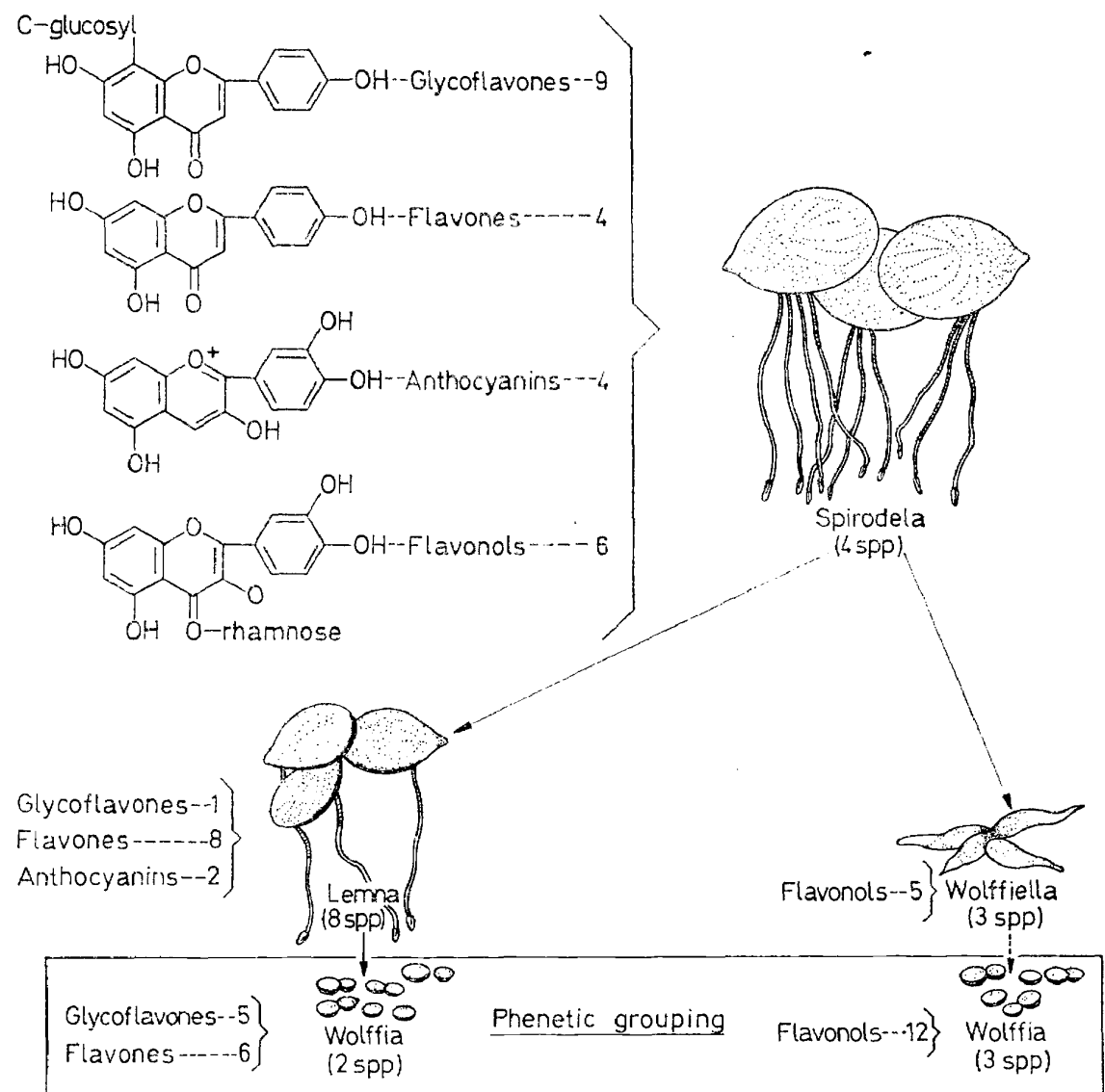

Figure 6. Hypothetical relationships in Lemnaceae. Morphological reduction is believed to have given rise to Wolffa and Wolffiela from ancestral prototypes similar to Spirodela. This reduction is also paralleled by a reduction in the kinds of secondary compounds produced. However, the chemical data suggest that Wolffia, as classically circumscribed, is biphyletic, the group of species without flavonols coming from a Lemna-like line; the group possessing only flavonols arising from some ancestral line perhaps unrelated to the Lemna group. (Based on data from McClure ${ }^{68}$ )

The chemical data are intriguing because these also point to a phyletic reduction series, paralleling that of the morphological. Spirodella contains four flavonoid types: (i) anthocyanins, (ii) flavones, (iii) glycoflavones, and (iv) flavonols: Lemna possesses (i), (ii), and (iii); Wolffia (ii) and (iii); and Wolffella only (iv) (Figure 6). The flavonoids of Wolffia and Wolffella are particularly interesting. These two genera are distinguished primarily by their vegetative shapes, Wolffia being more nearly isodiametric, Wolffiella being more nearly linear. Wolffia, then, appears to be a taxonomic category 
B. I. TURNER

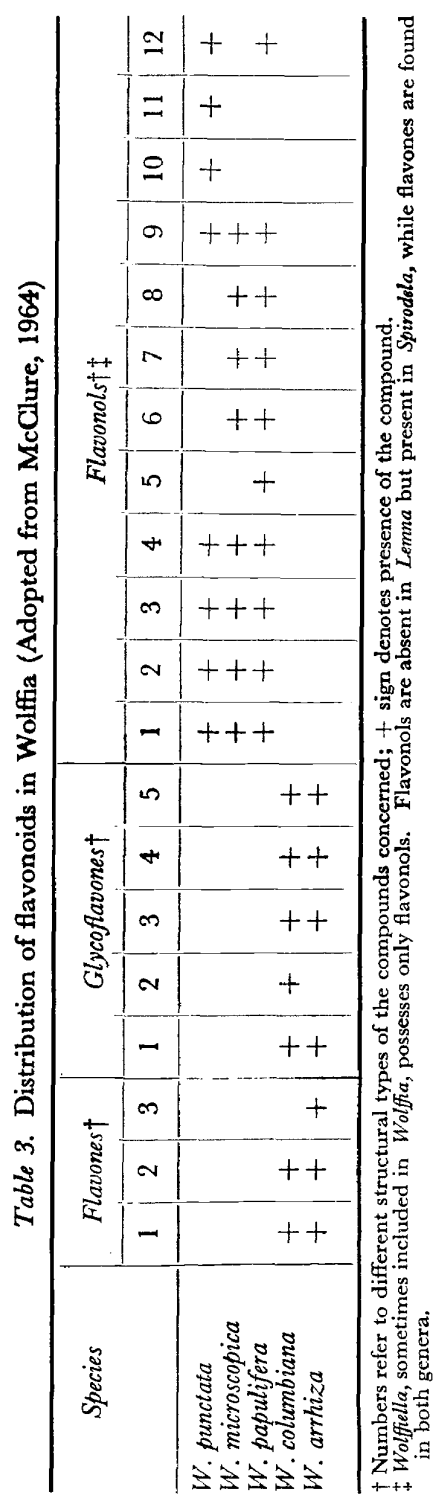




\section{PLANT CHEMOSYSTEMATICS AND PHYLOGENY}

which has been erected to include those species of the Lemnaceae which are devoid of exomorphic characters. The flavonoid data (Table 3), however, suggest that this grouping is perhaps not a monophyletic one, in fact, it suggests that $W o l f f a$, as presently constituted, is biphyletic, containing species derived through a Lemna-like line and another stemming from a Wolffella-like element. It will be most interesting to see if a parallel reduction series might not be found in yet other chemical groups within this complex. Most important for the purposes of this symposium, we have in Wolffia an example where the chemical data have suggested a phyletic model which could hardly have been proposed by exomorphic data, but surely an exceptional case among the higher plants generally, for most chemical data are likely to be used to support or deny those phyletic models already proposed by plant systematists $^{3}$.

Clearly, in the several examples cited above, the chemical data, after structural determinations have been made, must be evaluated in different ways, effective interpretation depending in large measure upon the structures concerned. Where the secondary compounds are quite different it may perhaps be inferred that the metabolic pathways leading to their production are quite different and, consequently, more phylogenetic emphasis might be placed upon distributional data of such compounds than would ordinarily be expected. An example of this type has been the phylogenetic conclusions drawn out of surveys for the red and yellow pigments (betacyanins and betaxanthins). These pigments are confined to the order Centrospermae and, unlike the common anthocyanins and carotenoids which comprise the red and yellow pigments of most other angiosperm groups, the betacyanins and betaxanthins are nitrogenous compounds which appear to be unrelated both chemically and biosynthetically to the former. Mabry ${ }^{72}$ has recently reviewed the literature bearing on the phylogenetic implication of these data and pertinent comments from his paper follow:

"... The taxonomic reliability of the betacyanins and betaxanthins rests not only on their chemically unique structures and the observation that their distributions are limited to the Centrospermae, but also on the fact that the pigments are mutually exclusive with the much more widely distributed anthocyanin pigments (although other classes of flavonoid pigments occur in the Centrospermae). For these reasons, along with morphological considerations, the Order Centrospermae has been recognized as containing the ten betacyanin families: Chenopodaceae, Portulacaceae, Amaranthaceae, Nyctaginaceae, Phytolaccaceae, Stegnospermaceae (often treated as a subfamily of the Phytolaccaceae), Aizoaceae, Cactaceae and Didieraceae. ...

". . . Betacyanins and betaxanthins apparently developed solely in the Centrospermae at a very early time, perhaps even before the anthocyanins appeared generally in the angiosperms. Several classes of flavonoids other than the anthocyanins do occur in the betacyanin families. Although detailed knowledge of the biosynthetic relationships among the flavonoids is not available, it is known, however, that most, if not all, flavonoids including the anthocyanins are formed from similar precursors, presumably chalcones. Furthermore, the in vivo transformations of either chalcones or other more highly oxidized flavonoids to anthocyanins is probably not enzymatically complex. Therefore it appears that the betacyanin families did not evolve pathways to the anthocyanins because the betacyanin pigments perform the same function in these families that is filled by an thocyanins in other families. ..." "... While the Centrospermae is perhaps not any better defined by the betacyanin data, the latter do, however, contradict the arrangement of the families as proposed by Hutchinson, for he would disperse several of the taxa among quite different, supposedly phyletic, lines. ..."

The betacyanin story is one, if not the best, example of how micromolecular data might bear upon phylogeny, particularly at the family level or higher, where new data are especially needed. A similar study has been the 


\section{B. L. TURNER}

surveys of $\mathrm{Kjaer}^{73}$ and others for the sulphur-containing isothiocyanates. These compounds have been found repeatedly in the Capparidaceae, Cruciferae, Moringaceae, and Resedaceae but not in the Papaveraceae, hence the data support Takhtajan's views that the latter family belongs to a different phyletic line. These data, like those of the betacyanins, are also contrary to Hutchinson's treatment, for Hutchinson would place the woody Capparidaceae and Moringaceae in a fundamentally different phyletic group from that of the predominantly herbaceous Cruciferae and Resedaceae. Unfortunately, the isothiocyanates also occur sporadically in several widely separated families such as the Euphorbiaceae, Phytolaccaceae and Plantaginaceae. Exceptions to the betacyanin story have not been found, in spite of rather wide surveys for the pigment.

Several workers have suggested phyletic interpretations on the basis of surveys of a similar type, but most such attempts have left too many sampling gaps to be meaningful, or else the compounds were too erratic in their occurrence to justify undue enthusiasm ${ }^{4-6,74}$. Distributional surveys for secondary compounds will become much more meaningful after knowledge of their biosynthetic origins has accumulated. This point has been repeatedly emphasized by a number of workers ${ }^{74}$ and in at least one recent text ${ }^{75}$ on phytochemistry the secondary compounds are arranged according to the metabolic pathways leading to their production; e.g., acetic acid $\left(\mathrm{C}_{2}\right) \mathrm{n}$ derivatives; isoprenoid $\left(\mathrm{C}_{5}\right) \mathrm{n}$ derivatives; shikimic acid derivatives, etc.

In summary, micromolecular data of a chromatographic nature may be of considerable value in the assessment of hybrid problems, but their utility in resolving positional problems will almost certainly demand the chemical determination of the compounds concerned, along with biosynthetic information leading to their production. A similar parallelism will be noted under the discussion of Macromolecular Systematics which follows, except that the phyletic implications which evolve out of the comparative studies of structurally determined protein and polynucleotides (i.e., their residue sequences) are much more profound.

\section{MACROMOLEGULAR SYSTEMATICS}

\section{Serology}

Many plant taxonomists prior to 1950 thought of serology and chemical taxonomy as synonymous. Alston and Turner ${ }^{3}$ recently reviewed the contribution of serology to systematics and concluded that, while catalytic to positive thinking in some instances, it apparently created more disinterest in "chemistry" as an approach to plant taxonomy than it did enthusiasm. Moritz ${ }^{76}$, in a sobering review of some special features of serobotanical work has called attention to the fact that serology "is a zoological method" and that certain technical difficulties in serobotany make the approach unattractive to botanists generally.

In recent years, however, the long-favoured "precipitin" test has been replaced by the more qualitative methods of gel immunoelectrophoresis and this method, among others, has been successfully applied to selected problems. For example, Klozova and $\mathrm{Kloz}^{77}$ have used immunochemical methods to detect the hybrid Phaseolus vulgaris $\times P$. coccineus, the $\mathrm{F}_{1}$ possessing 


\section{PLANT GHEMOSYSTEMATICS AND PHYLOGENY}

a complementation of the distinctive parental protein lines, much as found in the flavonoids in hybrid Baptisias. (Interestingly enough, similar techniques could not distinguish between 14 species of Baptisia, in spite of the fact that 11 or more distinctive arcs could be detected in each of their spectra.) But, at best, the detection of interacting macromolecular bands by immunogenetic techniques reflects the activity of relatively few genes and, viewed in this light, it is doubtful that this approach, taken alone, will contribute significantly to problems of plant phylogeny, although it has high value for distinguishing among presumably homologous proteins ${ }^{78}$.

\section{Protein-band comparisons}

Unlike the secondary compounds discussed above, detailed structural information on macromolecular compounds is only now becoming generally available. To date, relatively complete structural data have been compiled for only a few kinds of proteins and the complete amino-acid sequence has been determined for only eight or so $^{79}$, in spite of the fact that several hundred or more have been isolated and/or detected by electrophoretic techniques $^{80}$. Most important for the purposes of this review, the amino acid sequence (primary structure) is known for only one or two plant proteins, cytochrome $c^{81}$ and papain (tentative sequence only) ${ }^{82}$, consequently most of the more enlightening macromolecular approaches, at least for higher plants generally, remain in the future.

Kaplan ${ }^{83}$, however, has pointed out that sequential studies of proteins need not be prerequisite for their use in phyletic studies. Other data, at present more readily obtained, such as temperature stability, electrophoretic mobility, immunological characteristics, coenzyme-enzyme relationships, etc., of appropriate enzymes can also be used in making phyletic dispositions.

Macromolecular compounds, moreover, like the secondary compounds, even without the more sophisticated characterizations, can be used to detect hybridization. Numerous techniques have been developed for the detection of protein bands by electrophoretic methods and these have been used with considerable success, especially by zoologists. Manwell et al. ${ }^{\mathbf{8 4}, 85}$ have reviewed the utility of haemoglobin bands for the detection of hybrids and more recently Crenshaw ${ }^{86}$ claims to have detected introgression in turtles by this approach. In fact, these techniques, for certain protein types such as the seed globulins and selected enzymes, are easier to apply and provide data more rapidly than do the techniques of paper chromatography ${ }^{87}$. Indeed, the plant taxonomist is certain to be impressed with the amount of new characters which might be acquired by these approaches. For example, using the comparatively simple techniques of column chromatography and gel acrylamide electrophoresis, Saran and Radola ${ }^{88}$ were able to detect over 50 water soluble proteins in the freshwater alga, Chlorella pyrenoidosa. More recently, techniques have been developed for twodimensional gel electrophoresis of proteins and, if specific protein types can be isolated, there exist fast "fingerprinting" techniques, using tryptic digests and thin layer polyacrylamide, for the detection of protein fragments or peptides $^{89}$. 


\section{B. L. TURNER}

Application of protein-band data to specific taxonomic problems in plant groups are relatively rare, although a number of workers have called attention to the systematic potential of such studies ${ }^{90,91}$. One of the more interesting contributions has been that of Johnson and Hall ${ }^{92}$ where proteinband data were used to advantage in their investigation of the complex genome relationships in Triticum.

\section{DNA hybridization}

Perhaps the most spectacular chemosystematic development to come out of the past decade has been the techniques developed by Bolton and McCarthy ${ }^{93}$ and others in which DNA is extracted from an organism and made to "hybridize" in vitro (presumably through nucleotide-sequence complementations) with the extracted DNA (or RNA) of another organism. The taxonomic implications of this work have been reviewed by several workers ${ }^{94,95}$ and it need only be noted here that comparative data of this sort until recently (1965), have been available only for species of the animal kingdom and microorganisms. However, Bolton ${ }^{96}$ and his colleagues have now obtained such data for certain higher plants. Surprisingly, the preliminary results indicate considerable genetic divergence between what are thought to be closely related taxa (e.g., Pisum, Vicia, and Phaseolus, all belonging to the family Leguminosae). Thus Bolton notes that "within the family Leguminosae the relative diversity as measured by these DNA interactions is at least as great as exists among orders of mammals as distantly related as men and mice". If the methods are developed further, e.g., by the techniques of McLaren and Walker ${ }^{97,98}$ and those of Gillespie and Spiegel$\operatorname{man}^{99}$ we can hopefully anticipate a set of numerically expressed relationship-figures which, in theory, purport to show the total similarities and/or dissimilarities between whole genomes. Nucleic acid hybridization, with present techniques, will probably not be very useful for those seeking information about the relationship between and among closely related plant taxa. But the approach, if data are obtained comparable to those obtained for the animal kingdom, is perhaps the only realistic one in the foreseeable future for getting at objectively determined relationships of families and the higher categories.

\section{Comparative structure}

It would be presumptuous to review here the background and voluminous literature which bear upon the more sophisticated implications of macromolecular systematics. This has been covered energetically by Lanni for microorganisms and viruses, and the recent symposium on Evolving Genes and Proteins $^{13}$ has brought together the views of experts in the field. These studies, while not immediately applicable to plant systematics, are nevertheless pertinent for their extrapolatory value and, consequently, the implications of this kind of work will be touched on briefly in the present paper.

Concepts arising out of molecular biology, from the standpoint of organismally-centred systematists, have had a certain familiarity, for it seems that molecularly oriented workers have chanced upon the evolutionary 


\section{PLANT CHEMOSYSTEMATICS AND PHYLOGENY}

theory quite independently of Darwin. Indeed, had the concept of organic evolution not been proposed by organismally-centred biologists, it almost certainly would have been pronounced by present-day chemists. In fact, many university courses in biochemistry are organized, often unconsciously, along an evolutionary framework, i.e., simple or "primitive" metabolic pathways are discussed first, and upon these the more complex systems are developed. That this framework may be correlated with what the biologist considers to be primitive versus advanced organisms often comes as a surprise to the chemists themselves.

Contemplation of molecular evolution is a rewarding intellectual experience, for any number of parallels can be made with comparable phenomena at the organism level (or vice versa). Thus there ought to be a field entitled "molecular ecology" in which the "competition" between enzymes and substrates under varying cellular environments might be studied; or a subfield entitled "molecular paleontology" (see additional comments, below) in which attempts are made to "dig out" of extant ${ }^{\dagger}$ genomes (either directly by the comparison of nucleotide sequences, or by inference from the primary structure of proteins) those macromolecular units now covered-over with the molecular debris of the ages, etc.

Certainly it is difficult to consider the systematic implications of the protein work of Ingram ${ }^{102}$, Zuckerkandl and Pauling ${ }^{103}$, and Margoliash and coworkers on cytochrome $c$ without a certain sense of awe. The work of Margoliash and coworkers on cytochrome $c$ is perhaps typical and this will be briefly reviewed here.

Cytochrome $c$, a component of the terminal respiratory chain of enzymes in aerobic organisms, is widely distributed in both the animal and plant kingdoms. The enzyme has been obtained in pure form from a number of species and comparative study of the primary structures has shown that closely related taxa possess similar cytochrome $c$ enzymes. By inference from these data it appears certain that:

1. cytochrome $c$ enzymes in all organisms are homologous;

2. by extrapolation, they arise from homologous gene loci;

3. each possesses an evolutionary history;

4. they have diverged from some ancestral prototype;

5. "phylogenies" of proteins can be traced;

6. inferred primitive type molecules can be reconstructed (both on paper and in the test tube);

7. molecular phylogenies can be tested statistically and possibly experimentally 105 .

In addition to the comparative studies on cytochrome $c$, extensive information exists on the amino-acid sequences of the haemoglobin molecule. Zuckerkandl and Pauling ${ }^{103}$ have, among others, recently reviewed the systematic import of these data and it appears that haemoglobin has evolved at a rate of about 1 amino-acid change or mutation every 10 million years.

$\dagger$ Extinct organisms may also be analysed for their fossil macromolecules ${ }^{100}$, e.g., Foucart et al. ${ }^{101}$ have reported on the fossil proteins of graptolites from paleozoic time, concluding, by amino acid analysis, that the major macromolecular units were scleroproteic in nature. The expected residues for chitin (as it is known today) were not found, nor was there any trace of cellulose. 


\section{B. L. TURNER}

A "unit evolutionary period" of 22.6 million years has been estimated for the mutation and/or fixation of an amino-acid in cytochrome $c^{104}$. This figure was based on a paleontologically determined period of 280 million years (i.e., the estimated divergence of the avian and mammalian lines). With this time unit as a standard, it is reckoned that the divergence of the fish from the bird-mammal line occurred about 460 million years ago; vertebrates from invertebrates at about 680 million years; and fungi from this animal-line about 1000 million years. As indicated, such time-units and extrapolations from these, have been established by reference to what is known of the fossil record. It will be most interesting to see what comes out of similar studies in the flowering plants, for a fossil record pointing to clear cut evolutionary lines in this group is lacking.

Comparative studies of proteins are in their infancy and it is unlikely that any great accumulation of data which bear upon plant systematics generally will be had in this generation. However, biochemical techniques are developing rapidly and even if the instruments and know-how are not available to systematists of this day, it is likely that they will become so tomorrow. Relatively rapid methods have already been developed for the analysis of peptides derived from tryptic digests of protein ${ }^{\mathbf{1 0 6}}$ and as the techniques ${ }^{107}$ and instrumentation for peptide analysis become more sensitive, the high speed computer is certain to resolve the more tedious problems of interpretation and/or protein reconstruction ${ }^{108}$.

That future developments in chemosystematics might indeed be part of a Brave New World may be ascertained from a rather remarkable contribution by Pauling and Zuckerkandl ${ }^{105}$. In an imaginative article entitled "Chemical Paleogenetics: Molecular 'Restoration Studies' of Extinct Forms of Life" these authors comment:

“... Paleobiochemistry, through molecular restoration studies on the bases of existing related polypeptide chains provides the means of investigating the structure of such components for any part of the genome of extinct organisms. [for] . . . once the structures of ancestral polypeptide chains are known it will in the future be possible to synthesize these presumed components of extinct organisms ... [and] as information about various paleogenes belonging to a given group of extinct organisms will accumulate, some deductions concerning these organisms will be possible in relation to levels of biological integration higher than the level of individual macromolecules. When a fossil record is available, knowledge about the organisms concerned will go far beyond what has so far been believed possible. Important information will also be provided about forms that have left no fossil record whatsoever, such as many soft-bodied animals...."

\section{EPILOGUE}

There is certain to come a day when the present gap between organismally centred and molecularly centred systematics become sufficiently interfused so as to form a conceptual framework from which will grow remarkable insights into the whole of biological evolution. Neither group will develop these concepts alone, for the field of systematics is three-dimensional; there is no single focus. The molecular approach has done something for systematics unanticipated by taxonomists themselves; it has made systematics the ultimate approach of nearly all biological work. The molecular questions, what is it?, where does it occur? and what is it doing?, are taxonomic questions. The higher questions, when?, where? and how did it come about? 


\section{PLANT CHEMOSYSTEMATICS AND PHYLOGENY}

are phylogenetic questions. Taken together they constitute the spirit, if not the essence, of chemosystematics; indeed, all of biology.

Parts of this paper were presented at a symposium on "Newer Trends in Taxonomy" sponsored by the National Institute of Sciences of India, New Delhi, 1965. Chemosystematic studies on Baptisia were supported by National Institute of Health Grant11111. I am grateful to R. E. Alston, J. Harborne, and T. J. Mabry for helpful suggestions in the preparation of this presentation.

\section{References}

1 L. Constance. Taxon 13, 257 (1964).

2 B. L. Turner. In Newer Trends in Taxonomy. National Institute of Sciences, New Delhi, India (1966).

${ }^{3}$ R. E. Alston, and B. L. Turner. Biochemical Systematics. Prentice Hall, Inc., Inglesipe, (1963).

R. Hegnauer. Chemotaxonomie der Pfanzen. Vol. 1-5, Birhkauser, Verlag (1962-66).

5 C. A. Leone. (Ed.) Taxonomic Biochemistry and Serology. Ronald Press Co., New York (1964).

- T. Swain. (Ed.) Chemical Plant Taxonomy. Academic Press, London (1963).

7 R. E. Alston, T. J. Mabry, and B. L. Turner. Science, N.Y., 142, 545 (1963).

${ }^{8}$ H. Erdtman. In Chemical Plant Taxonomy. Academic Press, London (1963).

9 S. von Bortitz. Biol. Zbl. 83, 752 (1964).

10 B. H. Hoyer, B. J. McCarthy, and E. T. Bolton. Science, N.Y., 144, 959 (1964).

11 F. Lanni. In Plant Virology. University of Florida Press (1964).

12 K. N. Saxena, B. R. Seshachar, and J. R. Gandhi. Syst. Zool. 14, 33 (1965).

13 V. Bryson, and H. J. Vogel. (Ed.) Evolving Genes and Proteins. Academic Press, London (1965).

14 R. E. Alston. Lloydia. 28, 300 (1965).

15 R. R. Sokal and P. H. A. Sneath. Principles of Numerical Taxonomy. W. H. Freeman and Co. (1963).

${ }_{16}$ R. E. Alston. Taxon. 14, 84 (1965).

17 R. D. Gibbs. In Chemical Plant Taxonomy. Academic Press, London (1963).

${ }_{18} \mathrm{H}$. Erdtman. Personal Communication.

19 S. Rangaswami. In Symposium On Newer Trends in Taxonomy (Abstracts). Nat. Inst. Sci. India, New Delhi (1966).

20 M. J. Sackin. and P. H. A. Sneath. Biochem. J. 96, 70 (1965).

21 P. H. Davis, and V. H. Heywood. Principles of Angiosperm Taxonomy. Oliver and Boyd, London (1963).

${ }_{22}$ R. R. Sokal, J. H. Camin, F. J. Rohlf, and P. H. A. Sneath. Syst. Zool. 14, 237 (1965).

${ }^{23}$ E. Mayr. Syst. Zool. 14, 73 (1965).

24 W. Hennig. A. Rev. Ent. 10. 97 (1965).

${ }^{25}$ V. H. Heywood, and J. McNeill. (Eds.) Phenetic and Phyletic Classification. E. W. Classey, Ltd. Hampton (1964).

${ }^{26}$ J. H. Camin, and R. R. Sokal. Evolution 19, 311 (1965).

27 E. Mayr. Animal Species and Evolution. Harvard University Press, Cambridge (1963).

${ }^{28}$ E. A. Bell, and L. Fowden. In Taxonomic Biochemistry and Serology. Ronald Press Co., New York (1964).

${ }^{29}$ N. T. Mirov. Lloydia 26, 117 (1963).

${ }^{30}$ J. W. McClure, and R. E. Alston. Nature,Lond. 201, 311 (1964).

31 E. Anderson. Introgressive Hybridization. John Wiley \& Sons, New York (1949).

${ }^{32}$ R. E. Alston, and B. L. Turner. Proc. natn. Acad. Sci. U.S.A. 48, 130 (1962).

ss R. E. Alstor, and B. L. Turner. Am. J. Bot. 50, 159 (1963).

${ }^{34}$ J. Clausen, and W. M. Hiesey. Proc. natn. Acad. Sci. U.S.A. 46, 484 (1960).

${ }^{35}$ H. H. Smith, and D. V. Abashian. Am. J. Bot. 50, 135 (1963).

${ }^{36}$ E. Nowacki, and D. B. Dunn. Genet. pol. 5, 47 (1964).

${ }^{87}$ H. H. Smith. Am. Nat. 99, 73 (1965).

${ }^{\text {s8 }}$ C. R. Parks Am. J. Bot. 52, 309 (1965). 


\section{B. L. TURNER}

${ }^{39}$ J. McHale, and R. E. Alston. Evolution. 18, 304 (1964).

40 D. M. Smith, and D. A. Levin. Am. J. Bot. 50, 952 (1963).

${ }^{41}$ G. L. Stebbins, B. L. Harney, E. L. Cox, J. N. Rutger, G. Jelencovic, and E. Yagil. Am. J. Bot. 50, 830 (1963).

42 A. O. Taylor. New Phytol. 63. 135 (1964).

${ }^{43}$ A. M. Torres, and D. A. Levin. Am. J. Bot. 51, 639 (1964).

44 P. M. Harney, and W. F. Grant. Am. J. Bot. 51, 621 (1964).

${ }^{45}$ B. G. Brehm, and M. Ownbey. Am. J. Bot. 52, 811 (1965).

${ }^{46}$ D. A. Levin. Am. J. Bot. 53, 238 (1966).

${ }^{47} \mathrm{G}$. Hunter. Unpublished work, Univ. of Texas. (1965).

${ }^{48}$ O. Stromnaes, and E. D. Garber. Bot. Gaz. 105, 363 (1963).

${ }^{49}$ N. T. Mirov. In The Physiology of Forest Trees. Ronald Press Co., New York (1958).

${ }^{50}$ N. T. Mirov. Techn. Bull. U.S. Dep. agric. No. 1239. 1 (1961).

${ }^{51}$ M. H. Bannister, H. V. Brewerton, and I. R. C. MacDonald. Svensk Papp-Tidn. 62, 567 (1959).

52 M. B. Forde. N. Z. J. Bot. 2, 53 (1964).

${ }^{53}$ D. E. Stone, G. A. Adrouny, and S. Adrouny. Brittonia 17, 97 (1965).

${ }^{54}$ R. E. Alston. In Biochemistry of Phenolic Compounds. Academic Press, London (1964).

${ }^{55}$ D. B. Horne. Doctoral Dissertation, University of Texas (1965).

${ }^{56} \mathrm{~K}$. Baetcke. Doctoral Dissertation, University of Texas (1965).

57 E. von Rudloff. Gas Chromat. 3, 390 (1965).

${ }^{58}$ F. M. Couchman, and E. von Rudloff. Can. J. Chem. 43, 1017 (1965).

${ }^{59}$ D. B. Horne. Am. J. Bot. 51, 687 (1964).

${ }^{60}$ R. E. Alston, H. Rösler, K. Naifeh, and T. J. Mabry. Proc. natn. Acad. Sci. U.S.A. 54, 1458 (1965).

${ }^{61}$ W. L. Ellison, R. E. Alston, and B. L. Turner. Am. J. Bot. 49, 599 (1962).

${ }^{62}$ H. Lorenz, and J. Scholz-Schaeffer. Z. Pfiüücht. 52, 13 (1964).

${ }^{63}$ H. R. Holbo, and H. N. Mozingo. Am. J. Bot. 52, 970 (1965).

${ }^{64}$ R. E. Alston, et al. Unpublished work; J. Harborne. Unpublished work.

65 M. F. Granmer, and T. J. Mabry. Phytochemistry 5, 1133 (1966).

${ }^{66}$ M. F. Cranmer, and B. L. Turner. Evolution 20, (1967). In press.

${ }^{67}$ E. A. Bell. In Comparative Phytochemistry. Academic Press, London (1966).

${ }^{68}$ J. McClure. Doctoral Dissertation, The University of Texas (1964).

${ }^{89}$ A. Arbor. Proc. R. Soc., Ser. B 91, 96 (1920).

70 A. Lawalree. Bull. Soc. R. Bot. Belg. 77, 27 (1944).

${ }^{7}$ A. L. Takhtajan. Essays on the Evolutionary Morphology of Plants. Leningrad Univ. Leningrad, p. 62 (1954). (Trans. Multiprint, Inc., New York).

72 T. J. Mabry. In Comparative Phytochemistry. Academic Press, London (1966).

${ }^{73}$ A. Kjaer. In Comparative Phytochemistry. Academic Press, London (1966)

${ }^{74}$ T. Swain. (Ed.) In Comparative Phytochemistry. Academic Press, London (1966).

${ }^{75}$ C. Mentzer, and O. Fatainoff. Actualities de Phytochimie Fondamentale. I. Masson et Cie., Paris (1964).

${ }^{76}$ O. Moritz. In Taxonomic Biochemistry and Serology. Ronald Press Co., New York (1964).

77 E. Klozova, and J. Kloz. Biologia Pl. 6, 240 (1964).

${ }^{78}$ A. C. Wilson, and N. O. Kaplan. In Taxonomic Biochemistry and Serology. Ronald Press Co., New York (1964).

${ }^{79}$ G. H. Dixon. In Essays in Biochemistry. Vol. II. Academic Press, London (1966).

${ }^{80}$ M. Dixon, and E. G. Webb. Enzymes. Longmans, Green and Co., London (1964).

s1 E. Margoliash, and E. L. Smith. In Evolving Genes and Proteins. Academic Press, New York (1965).

82 A Light, R. Frater, J. R. Kimmel, and E. L. Smith. Proc. natl. Acad. Sci. U.S.A. 52, 1276 (1964).

${ }^{83}$ N. A. Kaplan. In Evolving Genes and Proteins. Academic Press, New York (1965).

${ }^{84}$ C. Manwell, and C. M. A. Baker. Comp. Biochem. Physiol. 10, 39 (1963).

${ }^{85}$ C. Manwell, C. M. A. Baker, and W. Childers. Comp. Biochem. Physiol. 10, 103 (1963).

${ }^{86} \mathrm{~J}$. W. Crenshaw. Evolution 19, 1 (1965).

${ }^{87}$ D. Boulter, D. A. Thurman, and B. L. Turner. Taxon 15, 135 (1966).

${ }_{88}^{8}$ I. Sarang, and B. J. Radola. Mh. Chem. 96, 1413 (1965).

${ }^{89}$ H. Stegemann, and B. Lerch. Analyt. Biochem. 9, 417 (1964). 


\section{PLANT GHEMOSYSTEMATICS AND PHYLOGENY}

${ }^{90}$ D. J. Fox, D. A. Thurman, and D. Boulter. Phytochemistry 3, 417 (1964).

${ }^{91}$ O. Hall, and B. L. Johnson. Hereditas 48, 530 (1962).

${ }^{92}$ B. L. Johnson, and O. Hall. Am. J. Bot. 52, 506 (1965).

${ }^{93}$ E. T. Bolton, and B. J. McCarthy. Proc. natn. Acad. Sci. U.S.A. 48, 1390 (1962).

${ }^{94}$ B. H. Hoyer, B. J. McCarthy, and E. T. Bolton. Science 144, 959 (1964).

${ }^{95}$ B. H. Hoyer, E. T. Bolton, B. J. McCarthy, and R. B. Roberts. In Evolving Genes and Proteins. Academic Press, New York (1965).

${ }^{96}$ E. T. Bolton, R. J. Britten, D. B. Cowie, R. B. Roberts, P. Szafranski, and M. J. Waring. In Carnegie Instn. Yb. 64, 313 (1965).

97 Anne McLaren, and P. M. B. Walker. Genet. Res. 6, 230 (1965).

${ }^{98}$ P. M. B. Walker, and Anne McLaren. J. Mol. Biol. 12, 394 (1965).

${ }^{98}$ D. Gillespie, and S. Spiegelman. J. Mol. Biol. 12, 829 (1965).

${ }^{100}$ M. Blumer. Science 149, 722 (1965).

${ }^{101}$ M. F. Foucart, S. Bricteux-Gregoire, ch. Jeuniaux and M. Florkin. Life Sci. 4, 467 (1965).

${ }^{102}$ V. M. Ingram. The Hemoglobins in Genetics and Evolution. Columbia Univ. Press, New York (1963).

${ }^{103}$ E. Zuckerkandl, and L. Pauling. In Evolving Genes and Proteins. Academic Press, New York (1965).

104 E. Margoliash, and E. L. Smith. In Evolving Genes and Proteins. Academic Press, New York (1965).

${ }^{105}$ L. Pauling, and E. Zuckerkandl. Acta chem. scand. 17 (Suppl. No. 1), 9 (1963).

${ }^{106}$ C. H. W. Hirst. Ann. Rev. Biochem. 33, 597 (1964).

107 R. B. Merrifield. Science, $N, Y, 150,178$ (1965).

${ }^{108}$ D. F. Bradley, C. R. Merril, and M. B. Shapiro. Biopolymers 2, 415 (1964). 